\title{
Examining the Context of E-Dictionary Use in Language Studies
}

\author{
Tetiana Vakaliuk ${ }^{1, *}$ Oksana Chernysh $^{1}$ Karaferye Figen $^{2}$ Raul Ferrer-Conill ${ }^{3}$
}

\author{
${ }^{1}$ Zhytomyr Polytechnic State University, Ukraine \\ ${ }^{2}$ Kutahya Dumlupinar University, Turkey \\ ${ }^{3}$ University of Stavanger, Norway \\ *Corresponding author. Email: tetianavakaliuk@gmail.com
}

\begin{abstract}
E-learning industry is constantly expanding, offering an increasing array of E-learning tools to meet learners' needs and bridge the education gap. Convenience and accessibility make E-learning a significant global educating force. It is widely accepted that E-learning greatly contributes to life-long learning, providing access to the world-class educational resources, thus becoming a leafing type of education in the $21^{\text {st }}$ century. Drawing on E-learning industry, this article emphasizes the significance of electronic academic and educational resources use in the era of digitalization of the system of education. The survey used in the article reviews classification features of computer programs for educational purposes in which particular attention is attributed to Edictionaries. Since E-dictionaries have gained popularity as a user-friendly comprehensive source of meaningful data and proved to increase learners' productivity and boost their knowledge, in the article we investigate the distinctive features of E-dictionaries and highlight the importance of E-dictionaries in mastering professional skills and fostering international scientific cooperation. Furthermore, the investigation analyzes different approaches to the notion "E-dictionary". It proposes a critical review of characteristics of E-dictionaries. Our findings stress the importance of such parameters as the range and scope of dictionary material, information type of lexical units, peculiar patterns of dictionary arrangement, dictionary purposes as well as the arrangement of polysemous word meanings. Moreover, the findings highlight the key challenges in the compilation of Edictionaries. We believe the study contributes to the field by providing a comprehensive account of the most significant distinctive features \& productivity of E-dictionaries, which are among the widely-used educational resources in the era of digitalization.
\end{abstract}

Keywords: E-dictionary, E- dictionary compilation, Distinctive features, E-learning, Computer programs, Information technologies.

\section{INTRODUCTION}

The 21 st century world has already been changing to a more knowledge-based society. Due to the era of digitalization, the system of education needs renewing academic content as well as enriching it by means of electronic academic and educational resources, applications, podcasts etc. The rise of pocket electronic dictionaries (PEDs) in the early 2010s [1] and the current dominance of online electronic dictionaries (EDs) has critically shaped how the public learn or expand their vocabulary $[2$; 3]. To meet the requirements set by the world scientific and educational community, we should focus on the constant improvement of electronic resources. Moreover, we should take into consideration not only educational needs of the $21 \mathrm{st}$ century learners, but also psychological features of the learning process itself $[4 ; 5]$.

This study aims to assess the academic efficiency of EDs as educational resources regarding their standards and defining qualities. We believe that investigating the distinctive features EDs highlights their important role in mastering professional skills and fostering international scientific cooperation. Therefore, in this research, we highlight the characteristic features of EDs and emphasize the value of their compilation considering $\mathrm{ED}$ as an 
inevitably important source of encyclopedic as well as linguistic origin.

To account for the advancements in language information processing technology, to facilitate international cooperation, and to foster scientific development, the world community invests time and money in developing language databases (Academic Search Complete, American and French Research on the Treasury of the French Language, China Academic Journals Full-text Database, Linguistics Collection, MLA International Bibliography, Oxford Dictionaries Online, ProQuest Research Library Plus, etc.). Consequently, a compilation of EDs is viewed as one of the steps towards economic and scientific advancement.

\subsection{Theoretical background}

In recent years, researchers have become increasingly interested in computer programs for educational purposes [6]. The programs have already become greatly valued in teaching as well as selflearning. For instance, due to the benefits that computer software contributes to language learning, classroom management, self-assessment etc. and makes the process of education effective and efficient [7].

It is commonly suggested that E-learning industry contributes profoundly to better understanding of a learning material. Due to integration of multimedia content and highly interactive content of the lessons, learners become more engaged in their study. Elearning keeps them interested in the material and promotes a productive learning environment. Moreover, the use of ICTs in education boosts learners' curiosity, improves their skills and motivates to study further. In addition, it helps to be up-to-date and stay aware of all current trends in any field of science.

Furthermore, the use of information and communication technologies (ICTs) in education makes every type of learners engaged. To illustrate, audio learners can benefit from listening to topical podcasts; visual learners can appreciate a variety of pictures and photos and use them as prompts to facilitate their speaking skills; kinesthetic learners may find typing activities productive, thus improving their writing [8].

When E-learning turns into the object of study, it presupposes learners are familiar with the environment, and enables them to rediscover their identity while giving them the opportunity to communicate in linguistic and cognitive sense of meaning. Consequently, it helps to keep the right balance in learners' skills development.

Several studies suggest that according to their functions and educational purposes, all computer programs fall into several groups (see fig. 1) [9]. According to the type of educational activity, we differentiate among new material presentation, new material retention, and assessment and evaluation groups. According to metadata features, new material presentation group includes educational and demonstration sources. Educational sources include electronic course books, online tutorials and lectures as well as distance courses. Demonstration sources comprise electronic atlases, museum guides, video and slide shows, albums and photo galleries and others.

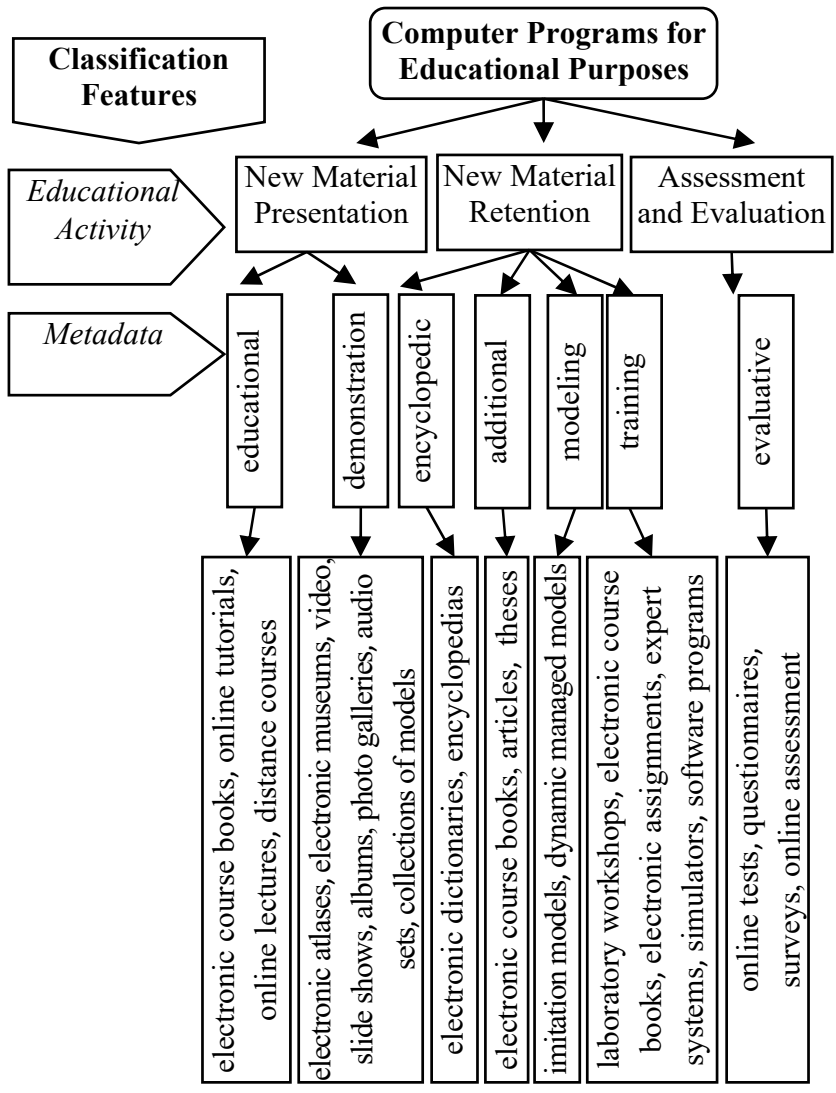

Figure 1. Classification of Electronic Resources for Educational Purposes. Adapted from [10]

New material retention group is divided into encyclopedic, additional, modeling and training (practical) sources. Encyclopedic references comprise E-dictionaries, encyclopedias and course books. Additional sources include books, articles, and theses. Training sources include electronic assignments, expert systems, simulators and 
educational software. In addition, educational software has its own classification, where expert system for educational purpose stands out [10].

An expert system is viewed as a system that manages the process of studying a particular subject by means of providing a set of educational assignments and guidelines, error correction and knowledge assessment [10]. The example of such a system is an expert language training system (a translation system) which is aimed at studying all language aspects, vocabulary replenishment, word combinations, set phrases and speech patterns, automatic translation in particular [11].

Assessment and evaluation group includes online tests, quizzes, questionnaires etc. [12].

In the past few decades there has been a growing interest in the study of ED features. In other words, in the era of digital revolution, ED is steadily gaining popularity and has already become one of the most important tools to facilitate cross-cultural communication [13]. The beginning of E-dictionary era dates back to the late 1960s, when Webster's Seventh New Collegiate Dictionary was created with the purpose of computational exploration. At the same time a prototype of a modern ED was created by means of an electronic punch-card machine first use. It was an electronic lexicographical edition by Roberto Busa, who used automatic linguistic analysis and highly estimated its contribution to computer lexicography.

Science computer lexicography has been rapidly developing over the last several decades, though and has undergone three phases as the research puts it forth [14]:

- computer assisted paper lexicography;

- transfer of paper lexicographical editions to electronic media;

- E-dictionaries initially conceived for electronic environment.

Meanwhile, ED compilation has always been in the focus of such linguists as David Barnhart (2016), Grant Barret (2016), Barbara Kipfer (2019), Erin McKean (2013), Iwo Pogonowski (1997), Jesse Sheidlower (2012), Adeline Smith (2012), Ladislav Zgusta (2006), Edmund Weiner (2006) and many others. Recent publications give an overview of different approaches to the notion "E-dictionary" [15, $16]$, advantages and disadvantages of its use [17; 18], the specifics of its compilation [19] etc.
Moreover, dictionary publishers have created genuine databases for data storage and manipulation (B+tree, ISAM). Consequently, in some works of metalexicographic research, the appropriateness of the term "E-dictionary" is questioned. As a result, to highlight the difference between printed dictionaries and digital lexicographic information systems such alternative terms as "leximat" [20, p. 121], "multifunctional lexicographic database" [21, p. 327], "vocabulary information system" [22, p. 147] are proposed.

Nevertheless, the term "E-dictionary" is still widely used to refer to any reference material stored in an electronic form that provides information about spelling, meaning and usage [23]. Nowadays, ED is defined as a reference tool which is viewed as a collection of electronically structured data accessed with multiple devices, enhanced with a wide range of functionalities, and used in various environments [24, p. 146]. Such a dictionary means a computer database of the specifically coded entries to enable quick word search with regard to morphological form, and with the possibility of searching word combinations and changing translation direction [25, p. 67]. It is a new structured text including data represented in different media such as audio files, videos, graph-based views etc. that has a definite volume, a clear aim and serves a specific idea [26, p. 54]. Thus, the most characteristic features of ED are gathered as the following:

- a specific combination of text and hypertext form of lexical material representation [25, 22];

- availability of verbal as well as non-verbal means of lexical unit description [22];

- sufficient search facilities within dictionary wordlist as well as in various Internet sources [25].

Every ED has a different interface and incorporates various advanced search techniques, which makes the process of finding lexical data quicker and more flexible. ED designs including the use of hyperlinks, images and graphics, access to corpora concordances, availability of search functions by inverse indexes, anagrams, and phonetic similarities allow more complex search. Some scientists anticipate the possibility of simultaneous searches in different ED [23], searching for a word from its phonetics, spelling similarities, etymology, thematic area, semantic relations with other words (synonymy, antonymy, hyponymy) [27, p. 89], a part 
of speech etc. The inclusion of all these in ED is a very useful complement to linguistic information.

In addition, ED is interactive. The user can add a comment, such as a usage note, a context or a translation to a dictionary entry, which may be useful in future searches [11].

The modification of lexical data is typically a constant and continual process started again and again in the course of ED use. Moreover, it is also possible to copy lexical data directly from the dictionary, which is quite convenient and greatly simplifies the work on lexical material.

Furthermore, ED is greatly valued for their quick translation capability, data transport, thesaurus and even learning programs. The user can also obtain the necessary information through complementary dictionary attributes such as images and audio files. The use of those images and audio files is becoming common for ED since they help the user to understand the meaning of a word better and create a general mood of the user involvement. What is more, ED can be loaded onto personal computers, e-readers, tablets, smart phones etc. Such an advantage makes them a universal tool for professional advancement.

Due to the characteristics mentioned above, interactivity, variety and flexibility in particular, ED has already become a multidimensional global information resource providing access to the lexical data required and considerably reducing search time. Contrary to conventional paper dictionaries, which are viewed as static and out-of-date content in 5-6 years' time after they are published [14, 28], ED can easily be updated, which guarantees a quick, precise and exhaustive search with a variety of search criteria combined. This feature is very significant, as accurate and precise presentation of linguistic data is of crucial importance for constant professional language work including domain expertise, documentation authoring and translation, professional communication.

It makes sense, therefore, to consider ED as a special lexicographic resource which is characterized by non-linear textual structure inside and outside search, verbal and non-verbal information representation means, a compendious combination of phonetic, semantic, encyclopedic etc. information types and an easy access to other information resources. Therefore, here we aimed to investigate the distinctive features of ED that will contribute to a quality ED compilation.

\section{METHODOLOGY}

Based on the facts presented above, the significance of ED compilation is undisputable. However, it requires considerable efforts. It is a meticulous, time-consuming multistep procedure which requires the use of innovative methods and techniques, though, the results of it are inevitably important and fruitful for the society.

Our study was conducted in three stages. The first stage was the interview. In order to better understand the needs of ED users, we designed a questionnaire that included 9 questions. The questionnaire was proposed to 126 respondents, namely 105 undergraduate students who do Applied Linguistics, IT, Economics, Law, Finance and Accounting, and Engineering courses and form $88 \%$ of all the participants and 21 teachers (12\% correspondingly). All the participants have at least upper intermediate English level. They can communicate easily and spontaneously in a clear and detailed manner. The results of the questionnaire are illustrated in Table 1. In the questions suggested, the respondents were asked to select from a list of possible answers. Whenever appropriate, a write-in option was included and the respondents could voice their opinion on the issue.

Table 1. Questionnaire on ED use

\begin{tabular}{|c|c|c|c|}
\hline \multirow[t]{2}{*}{1.} & \multicolumn{3}{|c|}{ Do you use E-dictionaries? } \\
\hline & yes $\square$ & no $\square$ & \\
\hline 2. & \multicolumn{3}{|c|}{ Why do/don't you use E-dictionaries? } \\
\hline 3. & \multicolumn{3}{|c|}{$\begin{array}{l}\text { How much time do you usually spend on looking up a } \\
\text { word in E-dictionaries? }\end{array}$} \\
\hline 4. & \multicolumn{3}{|c|}{ How often do you use E-dictionaries? } \\
\hline & often $\square$ & sometimes $\square$ & Idom $\square$ \\
\hline 5. & \multicolumn{3}{|c|}{ What E-dictionaries do you usually use? } \\
\hline & $\begin{array}{l}\text { a PC based } \\
\text { dictionary } \square\end{array}$ & \begin{tabular}{|l|l|}
$\begin{array}{l}\text { a smartphone based } \\
\text { dictionary }\end{array}$ & an \\
dic
\end{tabular} & $\begin{array}{l}\text { electronic } \\
\text { ctionary } \square\end{array}$ \\
\hline 6. & $\begin{array}{l}\text { What are the advant } \\
\text { Name at least } 3 \text {, plea }\end{array}$ & $\begin{array}{l}\text { tages of E-dictionaries } \\
\text { ase. }\end{array}$ & that you use? \\
\hline 7. & $\begin{array}{l}\text { What are the disad } \\
\text { use? Name at least } 3\end{array}$ & $\begin{array}{l}\text { dvantages of E-diction } \\
3 \text {, please. }\end{array}$ & aries that you \\
\hline 8. & $\begin{array}{l}\text { What other features } \\
\text { have? }\end{array}$ & s of E-dictionaries wou & uld you like to \\
\hline & grammar supplemen & nts, exercises, tests and & quizzes $\square$ \\
\hline & topical vocabulary s & sets, topical podcasts $\square$ & \\
\hline & others (please, speci & ify) $\square$ & \\
\hline 9. & Rate existing E-dicti & tionaries. & \\
\hline & very good $\square$ & $\operatorname{good} \square$ & very bad $\square$ \\
\hline
\end{tabular}


126 respondents were first asked if they use ED or not. Those who do had to clarify then a dictionary type, its model and features, state what they use it for and how often, as well as specify its advantages and disadvantages. Those who do not use ED were asked to give a reason.

The second stage of our study was to compare and critically analyze the data. To add objectivity to our study, we used the elements of numerical computing, to receive objective and relevant data.

The analysis of our respondents' answers proves that the majority of them prefer to use ED. However, some people prefer to refer to traditional paper dictionaries to thoroughly analyze linguistic data and not to be distracted by ED interactivity and hypertextuality (see fig. 2). Moreover, it spares their eyesight.

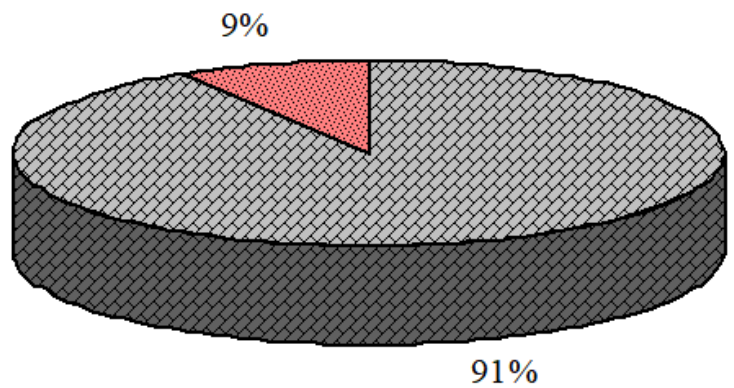

\section{囚EMD users 圈 paper dictionary users}

Figure 2 ED versus paper dictionary use

The most popular EDs are found to be The Oxford Advanced Learner's Dictionary of Current English (OALDCE), The Cambridge Advanced Learner's Dictionary (CALD), The Longman Dictionary of Contemporary English (LDOCE), The Collins English Dictionary (CED), The MerriamWebster's Learner's Dictionary (MWLD), and The Macmillan English Dictionary for Advanced Learners (MEDAL) (see fig. 3).

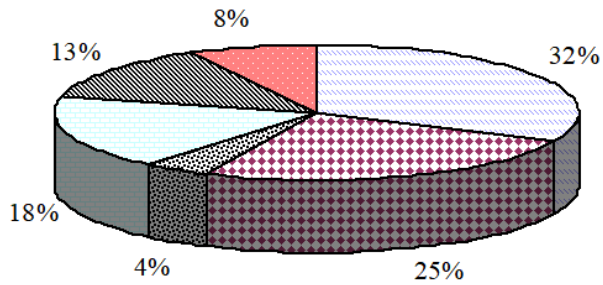

$\square$ OALDCE

Figure 3 ED use
To look at each of the ED stated by our respondents briefly; OALDCE by Oxford University Press is one of the oldest EDs [29]. Its printed editions date back to 1478 and have always been academic and educational resources of exceptional quality. Nowadays, the range of its editions includes dictionaries, English language teaching materials, university textbooks and many others.

CALD by Cambridge University Press is one of the most reputable EDs [30]. Cambridge University Press started functioning in 1584 and has been publishing dictionaries since 1995. In 1998, it offered its dictionary online which was completely free of charge.

LDOCE by Pearson Education Press is widely popular for The Longman Communication 9000 [31]. The Longman Communication 9000 represents the core of English language which is divided into high, medium and lower frequency words' bands, thus providing the users with the most significant lexical units for effective communication.

CED by Harper Collins Publishers is one of the largest publishing companies in the world [32]. CED is based on the Bank of English, the largest corpus of contemporary English texts. It has always been famous for providing thorough contextual usage of lexical items.

MWLD by Merriam-Webster FAQ is greatly valued for providing one of the best digital language references [33]. Merriam-Webster first printed dictionary was published in 1847 . Since then, the company has significantly upgraded and expanded. Currently, MWLD is a unique online-only reference which is regularly updated.

Lastly, MEDAL by Macmillan Publishers was first launched in 2009, though its printed version was issued in 2002 [34]. MEDAL was compiled by British and American lexicographers and now is widely known for its Open Dictionary that enables users to submit words.

All the EDs mentioned above are sufficient lexicographical editions known all over the world. They are highly rated by the scientific community and extensively used by online visitors. Consequently, these EDs of well-known reputable dictionary brands annually take leading positions in dictionary top lists [35].

Secondly, the respondents agree that EDs are rather convenient.

ED users as a rule need up to 15 minutes to get a detailed word profile, which is rather time-efficient 
(see fig. 4). In the analysis findings, the respondents believe that EDs are good. They are user-friendly, highly interactive, provide better visual prompts and make the process of finding the necessary material quicker (see fig. 5). Moreover, EDs simplify the process of editing text files and allow comparing the data. Furthermore, ED grammar supplements, exercises, tests, quizzes and topical podcasts are of a great benefit. It is obtained that EDs do not only explain the material better, but also provide some entertainment, turning the process of education into edutainment.

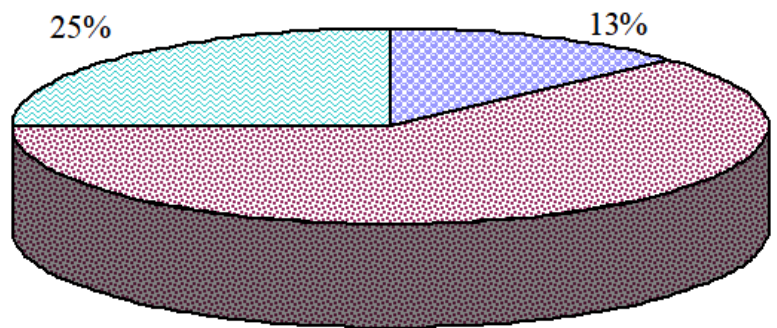

$62 \%$

$\square$ up to $5 \mathrm{~min} \quad$ : up to $10 \mathrm{~min} \square u$ to $15 \mathrm{~min}$

Figure 4 Time spent working with the dictionary

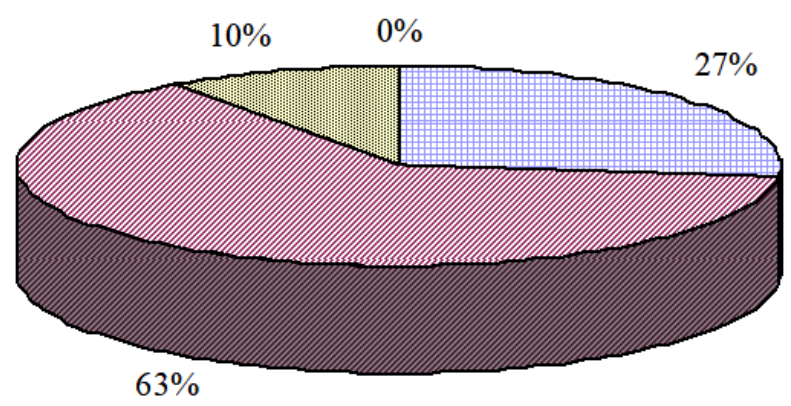

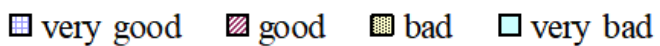

Figure 5 ED assessment

However, sometimes the users need more time to get used to a dictionary interface. In addition, it is rather preferable to get the main material first and then proceed to the additional one, though in some EDs the structure is opposite to that. What is more, ED hypertextuality interferes with the work and usually distracts the users, thus users' attention wanders and it becomes difficult to concentrate on the task.

Then, we turned to the third stage of our study. To better understand the nature of EDs, we decided to further investigate linguistic features of OALDCE, LDOCE, CED, MWLD, CALD and MEDAL.

\section{RESULTS AND DISCUSSION}

The analysis of ED linguistic features contributes to better understanding of its advantages and disadvantages. To analyze ED characteristics, we have considered the following parameters [36, 37]:

- $\quad$ range and scope of ED material;

- information type of ED items;

- patterns of ED arrangement;

- arrangement of polysemous word meanings;

- ED purposes (prescriptive versus descriptive, productive versus receptive).

The range and scope of ED material presupposes the analysis of entries density; temporal, spatial, social and frequentative presentation of the lexical material; type of language items registered; extent of concentration on lexical and encyclopedic data, and the number of languages involved [36, p. 31-32].

Firstly, entry density is a quantitative property of a dictionary, the precise size of the whole lexicon. The results of our investigation prove that paper dictionaries differ in wealth of recorded meanings, consequently, entry density could be used for their typological classification. The results are illustrated in Table 2. However, EDs have unlimited storage capability. As a result, it is not possible to consider the parameter in full.

Nevertheless, we will specify some other EDs' entry peculiarities. EDs cover a broad academic and educational spectrum, making their content available in different languages. To start with, OALDCE presents the material in more than 40 languages. CALD entry variety encompasses 20 languages. LDOCE, MWLD and MEDAL, on the contrary, publish their material in not so many languages. The list of languages include English, French, German, Italian, Spanish, Russian, Polish, Chinese, Japanese, Korean, Portuguese, Catalan, Czech, Turkish and other languages.

Secondly, temporal, spatial, social and frequentative presentation of the lexical material enables synchronic and diachronic language study, its national standard and regional varieties as well as its frequency. The study proves that the ED's coverage is predominantly restricted by time period. EDs tend to constantly update language material providing lexical items with wide usage. 
Table 2. The range and scope of ED material

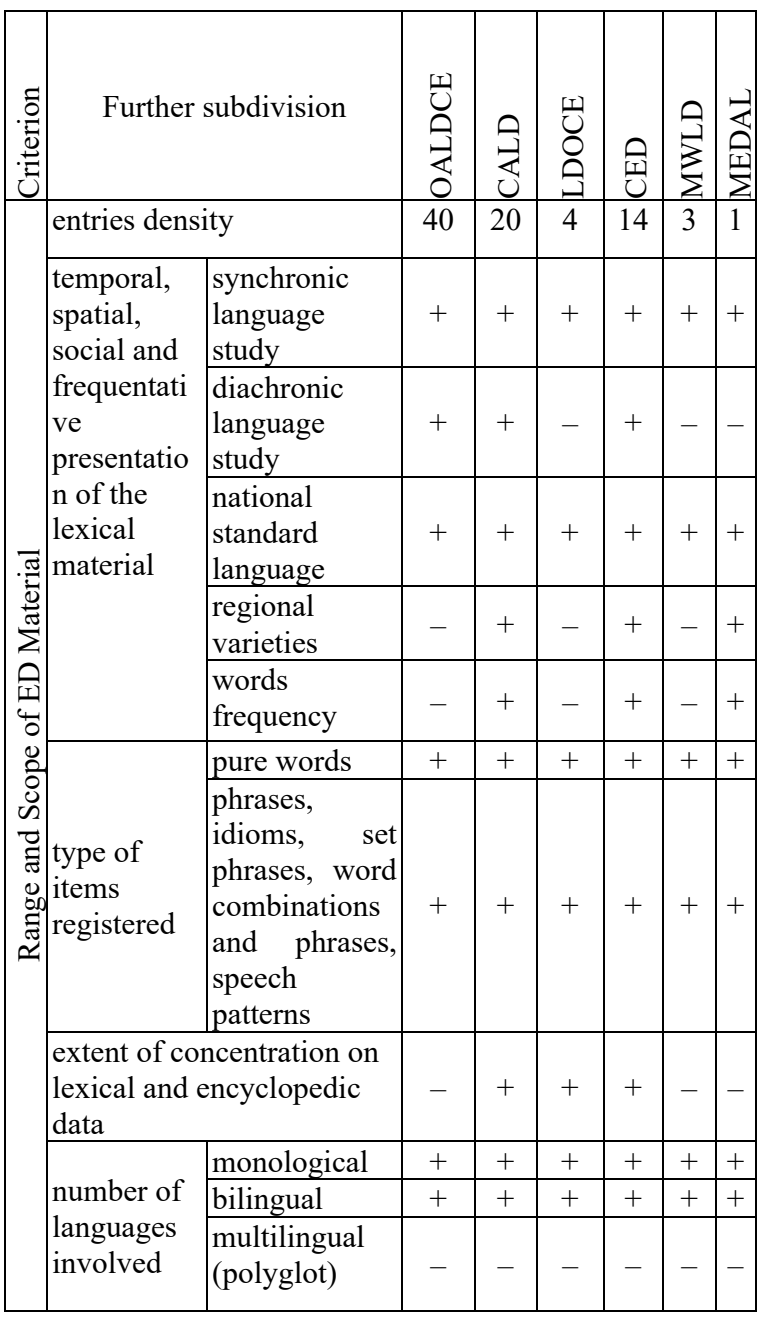

However, some EDs include the elements of diachronic language analysis, which may be of great importance for the readers interested in diachronic language studies. For example, CED demonstrates words' recorded usage by years. ED users have the possibility to track the word usage and consider its importance in modern English (see fig. 6).

\section{Trends of \\ orchard}

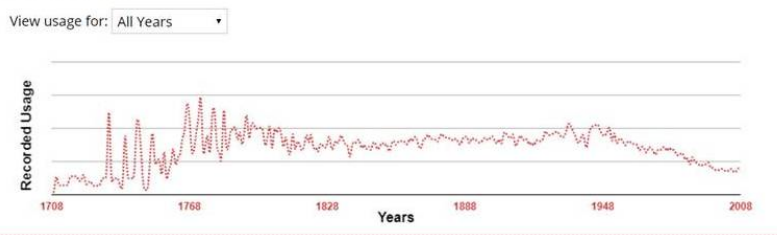

Figure 6 Word Recorded Usage by Years

EDs focus on national standard language, though some EDs also register regional varieties that may be needed for a further study.
Moreover, it contributes to effective cross-cultural communication and definitely widens ED users' horizon. It may be done with the help of a footnote or a remark to a word definition, for example:

"chamber: (Indian English)

an office, especially of

a person in an important position" (CALD).

Word frequency, territory and social environment of lexical items are rarely stated (see fig. 7) [37]. Nevertheless, it becomes possible to track all the above mentioned characteristics with the word recorded usage. Furthermore, some EDs state word frequency with the help of a word frequency sign, for instance let's consider CED word frequency comment:

\section{Definition of 'delegate' \\ delegate \\ Collins COBUILD \\ Word forms: plural, 3rd person singular present tense delegates, present participle delegating 40), past tense, past participle delegated (1)}

\section{Figure 7 Word frequency}

Thirdly, EDs may record not only isolated words, but also collocations, phrases, idioms, set phrases, and sometimes even speech patterns. They present synonyms and antonyms, highlight derivatives, divide lexical items into topical groups etc. EDs provide a detailed word profile that greatly contributes to users' vocabulary skills improvement.

Moreover, some EDs include unique treatment of metaphor, emphasizing that ordinary familiar words may have metaphorical meanings that users do not always realize. For example, MEDAL illustrates metaphorical meaning of the words related to the topic 'Illness':

\section{“METAPHOR}

Trying to recover from an illness or trying to stay healthy is like fighting a battle, with an illness as your enemy. Dying from an illness is like losing a battle.

Simple hygiene measures can help guard against infection.

I've been fighting off a cold all week.

The company is developing a new drug to combat malaria." (MEDAL) 
Furthermore, all EDs highlight word contextual usage, thus providing users with the rules of a lexical item usage. In addition, contextual usage accentuates regional and social environment characteristics, which makes a word profile full. What is more, EDs' hypertextuality makes it possible to include grammar reference with practical language usage, grammar exercises, tests, quizzes and even games. EDs offer topical word lists, text-checkers, diagnostic tests to assess users' reading level (OALDCE), translate option, a blog, word of the day section (CALD), hot topics section, vocabulary quizzes and exercises (LDOCE), trending words, latest words submission (CED), words trending now section (MWLD), synonyms of the month, buzzword section (MEDAL) and many others.

In addition, EDs may also have encyclopedic entries, such as proper names or geographical descriptions, hot social issues discussions, mass media reviews etc. This piece of information contributes not only to better understanding of a dictionary item, but also users' intelligence and general outlook.

According to the number of languages involved, EDs may be monological, bilingual, trilingual and multilingual (polyglot). Each ED type is unique for a language phenomenon study; for instance, monological dictionaries are often used for sufficient academic language study, whereas bilingual ones usually serve as translation dictionaries. The ED being analyzed may be either monological or bilingual depending on the option you choose.

Much prominence is given to the information type of ED items. The results are illustrated in Table 3.

Table 3. Information type of ED items

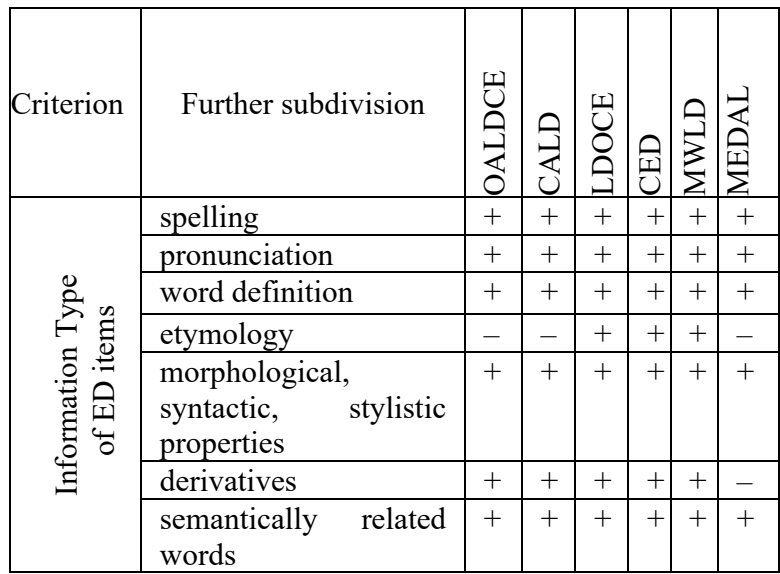

The results of the survey demonstrate that all EDs under analysis record spelling and pronunciation.
Moreover, EDs offer both English and American variants of spelling and pronunciation providing it with audio prompts, for example, as it is done in CALD:

$$
\begin{aligned}
& \text { "schedule } \\
& \operatorname{noun}[\mathrm{C}]
\end{aligned}
$$

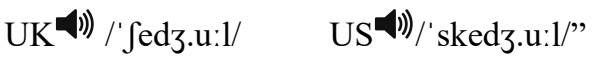

EDs give a word definition and emphasize its morphological, syntactic and stylistic properties, for instance, such a word profile we may find in CED:

"police

$$
(\text { pəli:s }(4))
$$

Word forms: 3rd person singular present tense polices $(4)$ ), present participle policing $(4)$ ), past tense, past participle policed $($ )),

Moreover, EDs provide derivatives and semantically related words etc, for example, LDOCE states:

\section{"happy}

Word family (noun) happiness $\neq$ unhappiness (adj ective) happy $\neq$ unhappy

(adverb) happily $\neq$ unhappily”

Word etymology is quite rarely emphasized in EDs. However, MWLD has a special section for that:

"History and Etymology for nature

Middle English, from Middle French, from Latin natura, from natus, past participle of nasci to be born - more at NATION"

Furthermore, EDs may provide illustrative examples to specify word meaning and usage. Such examples may be taken from literary sources, any written or recorded data, and even created simultaneously for the author's need. It greatly diversifies the content of the ED's entry. This information may also be a criterion for further ED classification.

In addition, there are several patterns of ED arrangement, such as:

- alphabetical arrangement, which is the most 
widely used one [38];

- semantic arrangement that presupposes the organization according to bonds of lexical item meaning. Thus, we have ED of synonyms, systematic ED etc.;

- casual arrangement, which creates a mixture of alphabetical and semantic ones.

The results are illustrated in Table 4.

Table 4. Pattern of ED arrangement

\begin{tabular}{|c|c|c|c|c|c|c|c|}
\hline Criterion & $\begin{array}{l}\text { Further } \\
\text { subdivision }\end{array}$ & 峁 & 是 & Ðூ & 至 & $\sum_{j}^{3}$ & 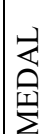 \\
\hline \multirow{3}{*}{$\begin{array}{l}\text { Patterns of } \\
\text { ED } \\
\text { Arrangement }\end{array}$} & alphabetical & + & + & + & + & + & + \\
\hline & semantic & - & - & - & - & - & - \\
\hline & casual & - & - & - & - & - & - \\
\hline
\end{tabular}

The results demonstrate that all EDs analyzed have alphabetical arrangement pattern, which is rather convenient and contributes to a quick word search.

What is more, the significance of polysemous word meanings arrangement in ED should be emphasized. The arrangement can be done according to:

- historical order, when the meanings are put in the sequence of their historical development;

- frequency, when the most common meanings come first;

- logical order to reflect the hierarchical relations between the meanings [39].

The table presents data on polysemous word meanings arrangement proving that predominantly EDs have the arrangement according to the frequency of polysemous word meanings. This makes the most significant information stand out.

The last criterion concerns ED functions (purposes), which is that EDs may have prescriptive (normative), descriptive, productive and receptive purposes. The results are illustrated in Table 6 .

Prescriptive (normative) purpose means that an ED does not only provide information about a word, but also emphasizes its correct usage in context. Descriptive purpose states that an ED records both standard language and dialectal words, archaisms, author's neologisms etc. thus, highlighting the whole spectrum of language varieties. It is obtained that all EDs under analysis perform the functions stated.

Table 5. ED purposes

\begin{tabular}{|c|c|c|c|c|c|c|c|}
\hline Criterion & $\begin{array}{c}\text { Further } \\
\text { subdivision }\end{array}$ & 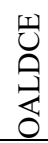 & 是 & 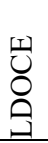 & 至 & $\sum_{i}^{9}$ & 究 \\
\hline \multirow{4}{*}{$\begin{array}{l}\text { ED } \\
\text { Purposes }\end{array}$} & $\begin{array}{l}\text { prescriptive } \\
\text { (normative) }\end{array}$ & + & + & + & + & + & + \\
\hline & descriptive & + & + & + & + & + & + \\
\hline & productive & + & + & + & + & + & + \\
\hline & receptive & - & - & - & - & - & - \\
\hline
\end{tabular}

Productive purpose is realized by active EDs [40, p. 106] dealing with encoding tasks. On the contrary, receptive purpose concerns passive EDs aimed at decoding tasks. Our EDs are active. We believe that the results of EDs' distinctive features analysis may contribute to the compilation of a model ED.

\section{CONCLUSIONS}

From the research that has been carried out, it is possible to conclude that EDs are efficient academic and educational resources with high standards, and a set of defining qualities. They record language data, emphasize morphological, syntactic and stylistic characteristics of lexical units, highlight their regional and social environment features, provide contextual usage, thus enabling ED users to get a detailed word profile. Moreover, EDs offer a great variety of synonyms, antonyms, collocations, idioms, set phrases related to the search word. EDs perform prescriptive, descriptive and productive functions providing users with the necessary language data. In addition, EDs greatly contribute to the development of users' language competencies, widen users' outlook and facilitate further language study.

Prospects for further research presuppose a profound study of technical features of ED architecture. It is now clear that we need to advance our understanding of ED software design adjusted to users' needs - not just educational but also psychological as stated - to provide more support to continuous learning of the (potential) users.

\section{REFERENCES}

[1] B. Filer, Paper or Electronic Dictionaries: A Comparison, in: P. Clements, A. Krause, H. Brown (Eds.), Transformation in language education, JALT, Tokyo, 2017, pp. 235-242. 
[2] S. Thornbury, How to teach vocabulary. Harlow, England: Pearson Education, 2008.

[3] J. Krajka, M.C. Campoy-Cubillo, Finding a place for e-dictionaries in language learning, teaching and assessment, INTED2020 Proceedings, 2020, pp. 1819-1828.

[4] J.T. Schmidt, M. Tang, Digitalization in Education: Challenges, Trends and Transformative Potential, in: M. Harwardt, P.J. Niermann, A. Schmutte, A. Steuernagel (eds) Führen und Managen in der digitalen Transformation. Springer Gabler, Wiesbaden, 2020 .

[5] OECD, Future of Education and Skills 2030: OECD Learning Compass 2030, 2019. https://www.oecd.org/education/2030-project/

[6] G. Matthias, F. Huber, G. Hagel, Gamification in software engineering education through Visual Novels, in: ECSEE '20: Proceedings of the 4th European Conference on Software Engineering Education, 2020, pp. 1-5.

[7] D. Kim, Learning Language, Learning Culture: Teaching Language to the Whole Student, ECNU Review of Education 3(3) (2020) 519541

[8] V. Pandolfini, Exploring the Impact of ICTs in Education: Controversies and Challenges. Italian Journal of Sociology of Education 8(2) (2016) $28-53$

[9] V.M. Demianenko, H.P. Lavrentieva, M.P. Shyshkina, Guidelines for the selection and use of electronic tools and resources for educational purposes, Kompiuter $\mathrm{u}$ shkoli ta simi 1 (2013) 44-48

[10] M.P. Shyshkina, Classification of E-Learning Tools, Naukovi zapysky. Seriia: Pedahohichni nauky 2 (82) (2009) 286-292

[11] R.H. Gouws, Article structures: Moving from printed to e-dictionaries, Lexikos 24 (2014) $155-177$.

[12] J. Majuri, J. Koivisto, J. Hamari, Gamification of education and learning: A review of empirical literature, in: J. Koivisto, J. Hamari (Eds.) Proceedings of the 2nd International GamiFIN Conference (GamiFIN 2018). P. 11-19. Eds. by CEUR Workshop Proceedings vol. 2186, 2018.
[13] T. Bothma, R.H. Gouws. e-Dictionaries in a Network of Information Tools in the eEnvironment, Lexikos 30 (2020) 1-28

[14] A. Shaikevich, Problems of the terminological lexicography, Moscow, 1983.

[15] Y.D. Dzhonh, Terms Learner's Dictionary in Modern Scientific Lexicography. Actual issues of Ukrainian linguistics: theory and practice 18 (2009) 41-49.

[16] N.M. Sinkevych, Modern Electronic Ukrainian Dictionary as a Base of Linguistic Analysis of the Word, Studies in lexicology and grammar of the Ukrainian language 10 (2011) 240-244.

[17] M. Kulchytskyi, Computer technology aspects of modern lexicographic systems creation, Ukrainian Lingua-Information Fund, NAS of Ukraine, 2002

[18] I. Biliatynska, Computer lexicography as a promising direction for the development of the dictionary compilation process, Applied Linguistics, 2013,

https://prlingv.at.ua/publ/komp_juterna_leksikog rafija_jak_perspektivnij_naprjamok_rozvitku_pr ocesu_ukladannja_slovnikiv/1-1-0-7.

[19] V.I. Perebyinis, E.P. Rukina, S.S. Khidekel, English-Ukrainian educational dictionary with methodological comments and grammar tables and grammar in Ukrainian, Vezha, Kyiv, 2002.

[20] S. Tarp, General Lexicographical Theory with Particular Focus on Learner's Lexicography. Lexicography in the Borderland between Knowledge and Non-Knowledge, Lexicographica Series Maior 134 (2008) 308.

[21] J. Pajzs, On the Possibility of Creating Multifunctional Lexicographical Databases, in: H. Bergenholtz, S. Nielsen, S. Tarp (Eds.) Lexicography at a Crossroads: Dictionaries and Encyclopedias Today, Lexicographical Tools Tomorrow, Peter Lang, 2009, pp. 327-354.

[22] C. Müller-Spitzer, Textual structures in electronic dictionaries compared with printed dictionaries: a short general survey. Dictionaries, An International Encyclopedia of Lexicography, Supplementary Volume: Recent Developments with Focus on Electronic and Computational Lexicography, 2014.

[23] H. Nesi, How learners of English as a Foreign Language Read and Interpret Dictionary Entries. 
The Use and Abuse of EFL Dictionaries, Lexicographica Series Maior 98 (2000) 162.

[24] G.M. De Schryver, Lexicographers' dreams in the electronic-dictionary age, International Journal of Lexicography, 16(2) (2003) 143-199.

[25] I.I. Zavaruieva, On one possibility of classifying electronic dictionaries, Journal of V.N. Karazin Kharkiv National University, series "Philology" 765 (50) (2007) 67-70.

[26] Ya.A. Parvanov, Notes on electronic lexicography, eprint arXiv: 1107.1753, 2011.

[27] W.S. Dodd, Lexicomputing and the Dictionary of the Future. Lexicographers and Their Works, Exeter Linguistic Studies 14 (1989) 83-93.

[28] E.V. Kuprijanov, Electronic dictionary classification as problem of modern computer lexicography, Journal of V.N. Karazin Kharkiv National University, series "Philology" 71 (2014) 29-33

[29] OALDCE Homepage, https://www.oxfordlearnersdictionaries.com/, 2020 .

[30] CALD Homepage, https://dictionary.cambridge.org/about.html, 2020 .

[31] LDOCE Homepage, https://www.pearson.com/english/catalogue/dicti onaries.html, 2020.

[32] CED Homepage, https://www.collinsdictionary.com/browse/, 2020.

[33] MWLD Homepage, https://www.merriamwebster.com/about-us/faq/, 2020.

[34] MEDAL Homepage, https://www.macmillandictionary.com/about.ht $\mathrm{ml} /, 2020$.

[35] BEOD Homepage, https://lemongrad.com/bestonline-dictionaries/, 2020.

[36] S. Landau, Dictionaries: The art and craft of lexicography, Cambridge University Press, Cambridge, 2004.

[37] R. Leščinskij, Linguistic and semiotic characteristics of English and Russian dictionaries: a comparative study, Coactivity: Philology, Educology 21(1) (2013) 35-44.
[38] P. Clements, A. Krause, H. Brown (Eds.), Transformation in language education, JALT, Tokyo, 2017

[39] R.R.K. Hartmann, G. James, Dictionary of Lexicography, Routledge, London, 1998.

[40] D. Tekorienè, N. Maskaliūnienè. "Lexicography: British and American Dictionaries", Vilnius University Press, Vilnius, 2004. 